\title{
Stratigraphy and Habitation Features at DIA.4 (JfE1-4), a Dorset Site in Arctic Quebec
}

\author{
IAN BADGLEY'
}

\begin{abstract}
The 1978 Tuvaaluk Programme excavation at DIA.4 (JfE1-4) revealed evidence of 15 habitation features in a stratified context. These features, comprising both semi-subterranean dwellings and tent emplacements, are summarized and stratigraphically organized into chronologically successive occupation phases at the site. Excavation resuits suggest certain methodological implications of importance to the interpretation of the Dorset settlement pattern in Ungava.
\end{abstract}

RESUMÉ. Au cours de la fouille du Programme TUVAALUK en 1978 au site DIA.4 (JfE1-4), nous avons reconnu 15 structures d'habitation dorsétienne dans un contexte stratigraphique. Elles comprennent des structures de creusement ainsi que de surface. Ces structures sont décrites et regroupées selon la stratigraphie en phases d'occupation successives au site. Les résultats de la fouille ont révélé certaines implications méthodologiques pour l'interprétation du mode d'implantation dorsétien dans l'Ungava.

\section{INTRODUCTION}

This paper presents a preliminary synthesis of the settlement and habitation data from the multi-component, stratified DIA.4 (JfE1-4) Dorset site in Arctic Quebec. This synthesis involves general consideration of cultural remains interpreted as representing habitation structures and the stratigraphic units associated with these structures. These data were recorded during the 1978 Tuvaaluk Programme excavation at the site.

For the purposes of this presentation, the term "settlement pattern" is defined as the spatial arrangement of habitation structures through time within the confines of the 'site'. Although approximating Chang's (1962:30) concept of "community pattern" and Trigger's (1968:60) "habitation" and "community layout" levels of interpretation, this definition does not include consideration of the socio-economic organization of the subject group or groups. At present, neither simultaneity of occupation of the structures nor the length of time and number of individuals involved in these occupations can be determined. In terms of the areal extent and complexity of the site, such evaluations would prove wholly unrealistic and unfounded; to date, only 240 of the estimated 1300 square metres constituting the principal area of Dorset occupation at the site have been excavated.* Also, the formal, distributional, and associational analysis of the approximately 18,000 lithic artifacts (detritus included) recovered in 1978 is far from complete.

'Assistant Director, Programme Tuvaaluk, Laboratoire d'Archéologie de l'Université du Québec à Montréal. P.Q. H3C 3P8

* An additional $297 \mathrm{~m}^{2}$ were excavated in this area during the 1979 Tuvaaluk Programme field season. Habitation data from this excavation are currently undergoing analysis and are not here included. 
Consequently, this discussion is limited to a brief morphological description of the habitation structures and, secondly, to the stratigraphic organization of the structures into a provisional chronological sequence of occupation within the area excavated in 1978.

\section{The DIA.4 Site (JfE1-4)}

DIA.4 (JfEl-4) is located on the southeastern extremity of Diana Island, in Diana Bay, northwestern Ungava Bay, at lat. N:60 $56^{\prime}$; long. W:69 $58^{\prime} 40^{\prime \prime}$ (Fig. 1). Prior to excavation, the principal occupation of the area of the site was

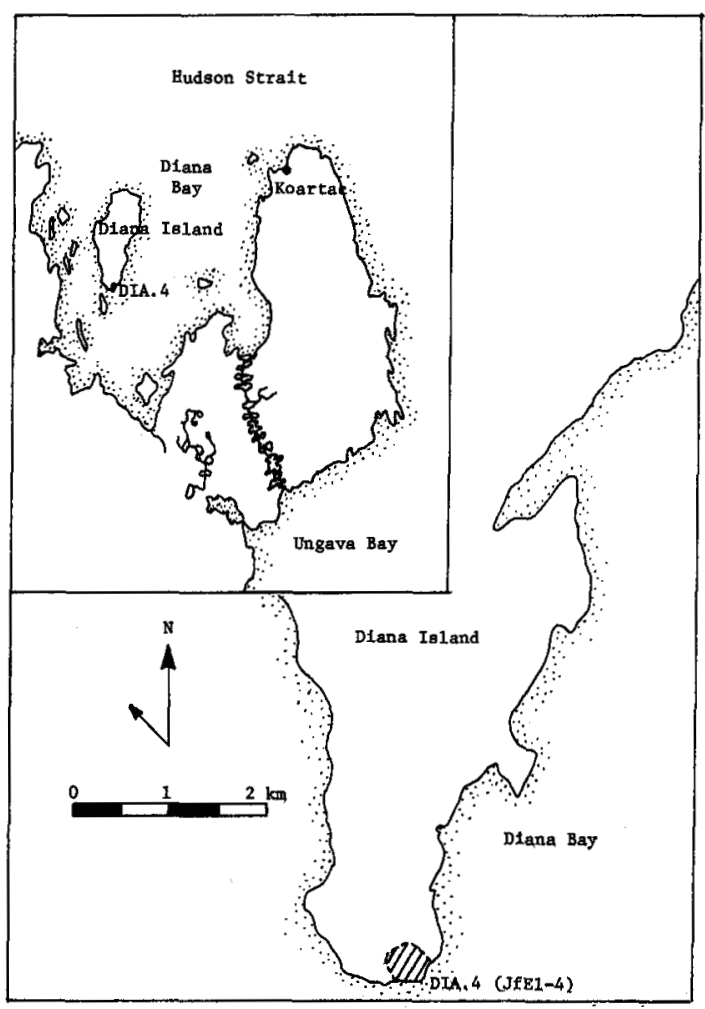

FIG. 1. DIA.4 (JfE1-4). 
perceived as comprising 7 semi-subterranean Dorset dwellings and a number of tent emplacements situated on a narrow series of southeasterly-descending raised beaches bordered on the north and south by linear bedrock outcrops. The structures occur between roughly 4.0 and $10.75 \mathrm{~m}$ a.s.l., with the semisubterranean dwellings clustered above ca. $6.20 \mathrm{~m}$ a.s.1. These latter dwellings are distinguished by shallow to relatively deep depressions of various sizes and contours containing a generally more luxuriant vegetation than the surrounding zones. Vegetation at the site is dominated by 'gramineae' and, in some zones, wet mosses.

Interest in DIA.4 stems directly from research conducted at the site by Patrick Plumet in 1973 and continued by Jean-Paul Salaün in 1974 and 1976. During these field seasons, 2 semi-subterranean structures (DIA.4-A and B) were excavated. One of these structures - DIA.4-A — produced a radiocarbon date of A.D. 1480 $\pm 90($ GIF-3002*) on wood charcoal from an undisturbed hearth. This late date not only extends the Paleo-Eskimo period in the Eastern Canadian Arctic by an additional 200 years but also allows speculation on the possibility of DorsetThule contact situations in Ungava; A date of A.D. $1140 \pm 80$ (GIF-4209) has been obtained on wood charcoal from a Thule structure situated on the southern coast of Diana Bay. Certain characteristics of DIA.4-A, including a semisubterranean entrance passage, a lateral hearth, the circular form of the dwelling, and its considerable depth, further suggest the possible assimilation of Neo-Eskimo architectural techniques by a Dorset population who maintained an Arctic Small Tood tradition lithic technology (Plumet, 1979).

Earlier research had also indicated that several of the semi-subterranean dwellings were associated with overlapping midden deposits, suggesting, therefore, an internal cultural stratigraphy for this area of the site. These circumstances would not only provide a means for determining relationships between the individual structures useful to the study of Dorset settlement patterning but also implied the possibility of isolating temporally successive artifact assemblages.

Thus, in order to clarify the chronology of occupation at DIA.4, the 1978 Tuvaaluk Programme field season was organized to include excavation of the midden deposits and the semi-subterranean structures $C$ and $\mathbf{G}$ immediately north of the 2 previously excavated dwellings. Research priorities focused on the determination of stratigraphic relationships between these dwellings and Structures A and B. During the 12-week field season (June 5 to August 24), excavation was extended to include a third semi-subterranean structure, DIA.4-E (Fig. 2). Within the $109 \mathrm{~m}^{2}$ excavated, 15 habitation features and/or occupation zones and 11 major stratigraphic units were eventually identified.

\section{The Stratigraphy}

Figure 3 provides a schematic representation of the stratigraphy recorded during 1978. The sequence comprises the surface vegetation and sod (Level I), four units of relatively pure, well-developed humus (Levels II, IIb, IV, and VI),

\footnotetext{
*Laboratoire du Radiocarbon du Commisériat à l'Energie atomique du C.N.R.S. (France).
} 


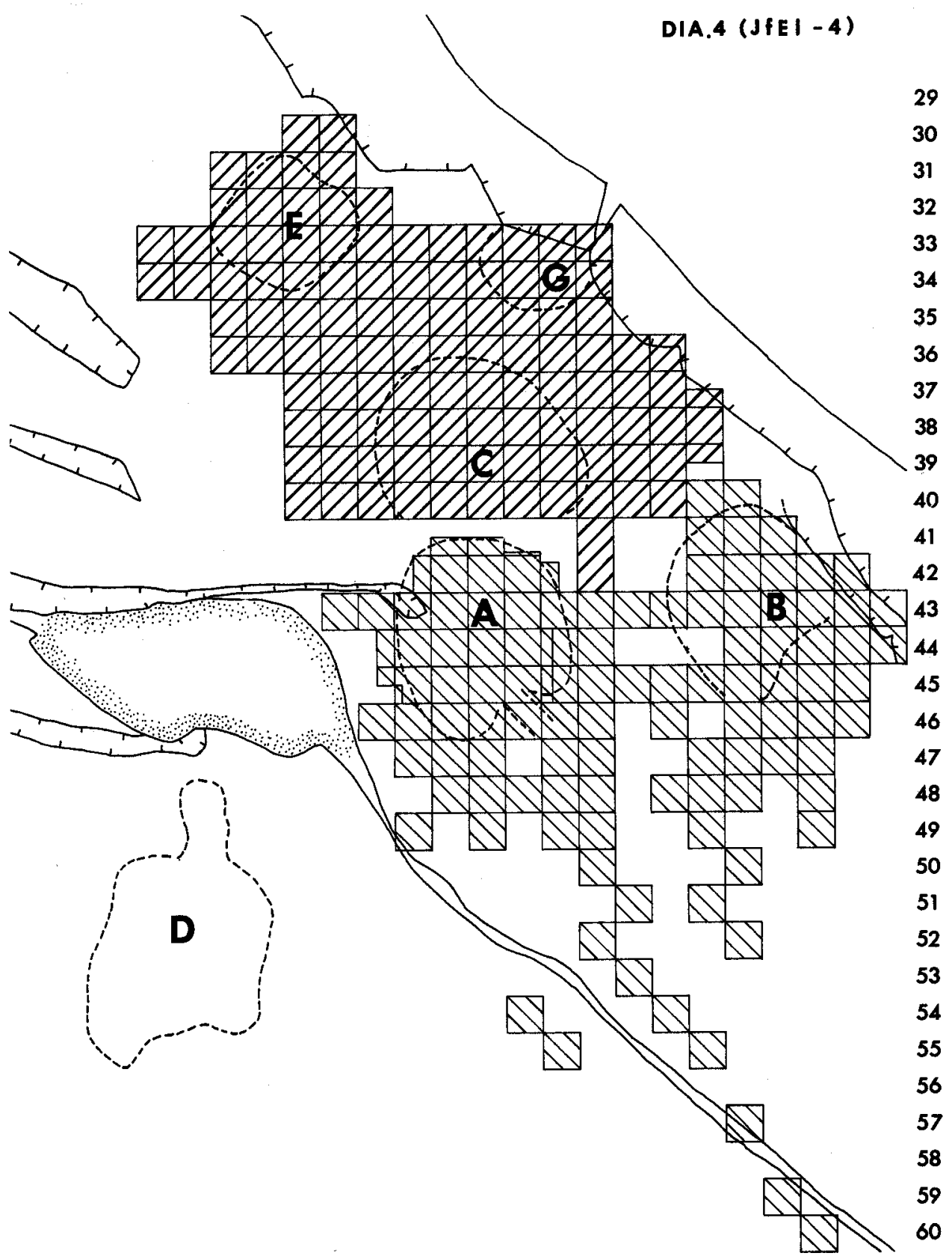

AE AD AC AB AA $Z$ W U PA Excarated in 1978

N DV Excavated in 1973,74 or 76

FIG. 2. DIA.4 (JfE1-4), Excavated area. 

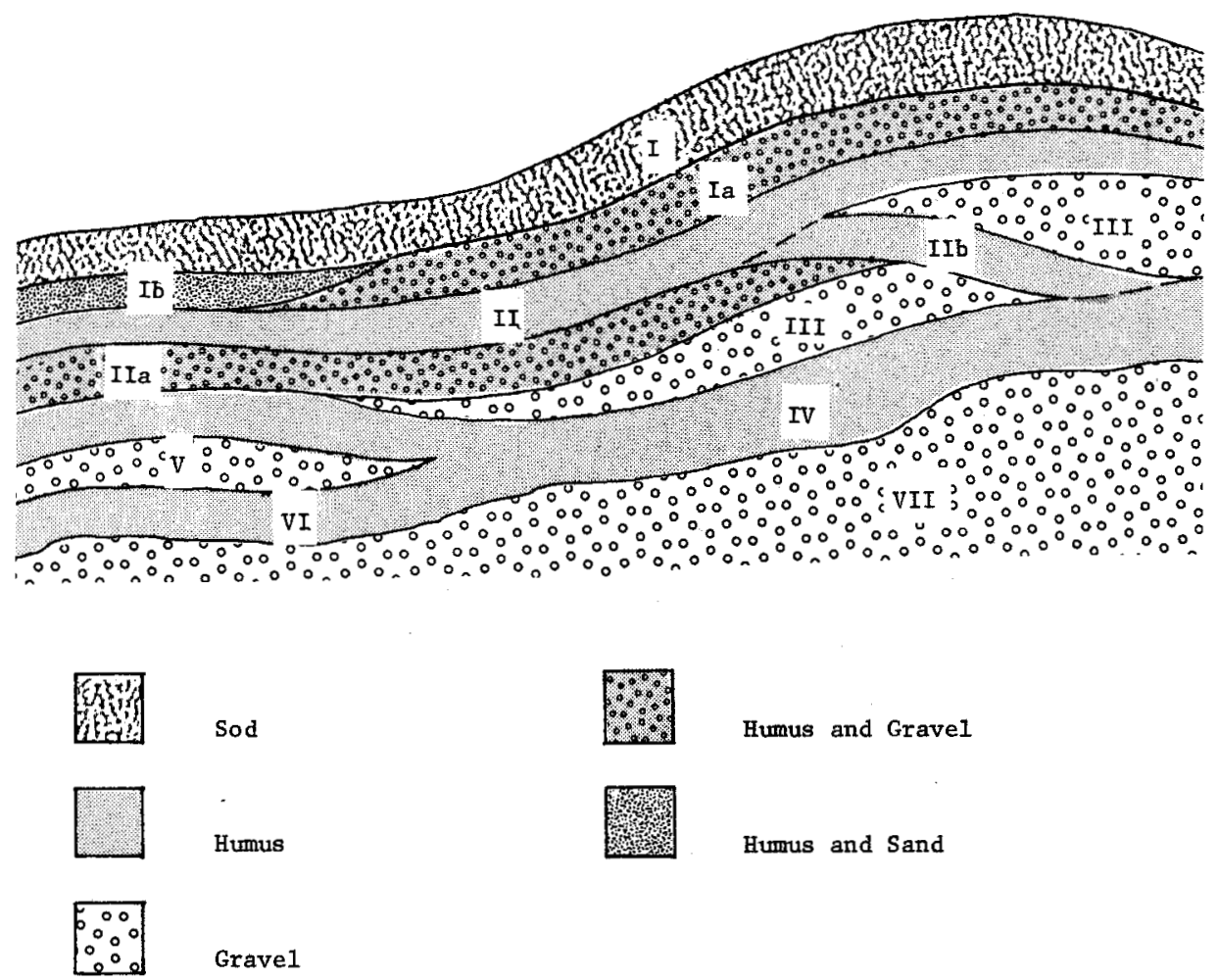

FIG. 3. Schematic representation of the stratigraphy, DIA.4 (JfE1-4), 1978.

three units of humus with gravel or sand admixture (Levels Ia, Ib, and IIa), and two gravel strata (Levels III and V). The underlying sterile sand and gravel beach deposit is designated Level VII. Excluding the sod and basal deposit, none of the units extend continuously across the excavated area. However, in terms of spatial distribution, all of the units are either wholly superimposed or partially overlapping. The depositional sequence and inter-relationships of the individual stratigraphic units is therefore clear. In the eastern and southeastern profiles (i.e., the zone of greatest stratigraphic development), the maximum depth of the sequence exceeds $45 \mathrm{~cm}$. The average thickness of the combined units across the excavated area is roughly $25 \mathrm{~cm}$.

With the exception of the gravel units V and VII and the Level I sod, all of the strata appear to be basically anthropogenetic in origin and relationships. The stratigraphy results, we believe, from successive constructional and/or occupational activities at the site. This hypothesis is suggested by the physical composition of the units and by the close spatial correspondence between the different units and the identified habitation features.

Speculations concerning the origins and associations of the stratigraphic units are summarized as follows. The horizontal configurations and composition of 
Levels Ia and Ib suggest, respectively, the interior and perimeter of two possible surface habitations, neither of which is structurally definable. Levels II and IIa appear to be associated with Structures C, E, and G. Whereas the former is provisionally interpreted as representing the principal occupation (or occupations) of these structures, the latter may represent decomposed sod blocks used in the walls of these dwellings or, possibly, re-occupations of the house depressions involving the clearing of previous occupational refuse. Unit IIa is not only spatially correspondent with these habitations but also attains its maximum thickness along the perimeters of these house depressions. Level III, the main component in the gravel wall foundation of the contiguous Structures $\mathrm{C}$ and $\mathrm{G}$, is presumed to originate from the construction of the latter dwelling. This hypothesis is based on the comparison of the volumes calculated for this gravel unit and the interior of Structure G. Level IIb, a limited humus lense occurring within Level III, is also considered to be associated with Structure G. Level IV represents a substantial midden consisting of well-developed humus interspersed with thin, discontinuous lenses of partially decomposed organic material. This midden appears to result from a particularly intensive and presumably lengthy use of this part of the site. The southeastern portion of this midden is underlain by Level $\mathrm{V}$ grave, a marine deposit attaining a maximum thickness of $c a .15 \mathrm{~cm} .{ }^{*}$ Cultural materials recovered from this unit are presumed to originate from the underlying VI, a thin humus layer occurring within a relatively well preserved house depression.

Finally, it should be noted that stratigraphic complexity and development of the individual units decreases markedly towards the west and northwest, zones of lesser intensity of occupation and fewer definable activity areas. Artifact density is correspondingly reduced in these zones of the excavated area.

\section{Habitation Features}

Habitation features include semi-subterranean dwellings (consisting of shallow to relatively deep depressions) and surface structures (regular and continuous stone alignments interpreted as tent emplacements). Organic materials, such as whalebone and wood, suitable as structural supports for these dwellings are absent from the 1978 excavation area. Although certain data allow speculation on the possible use of sod blocks in the walls of Structures C, E, and G, the architectural remains of the majority of the semi-subterranean dwellings are represented by gravel-rimmed depressions, the interior borders of which are frequently maintained by arrangements of vertically-placed stone slabs, blocks, or both. Internal cultural features indicating use of the depressions and stone alignments as habitations include flagstone pavements, stone-constructed hearths, slab-lined "boxes", and circular to oval storage pits (Fig. 4).

The degree of preservation of architectural elements delimiting the interior domestic areas of the structures is variable. For example, the peripheries of

*The marine origin of this deposit was verified in 1979 by Dr. Pierre Gangloff, geomorphologist, Département de Geographie, Université de Montreal. 

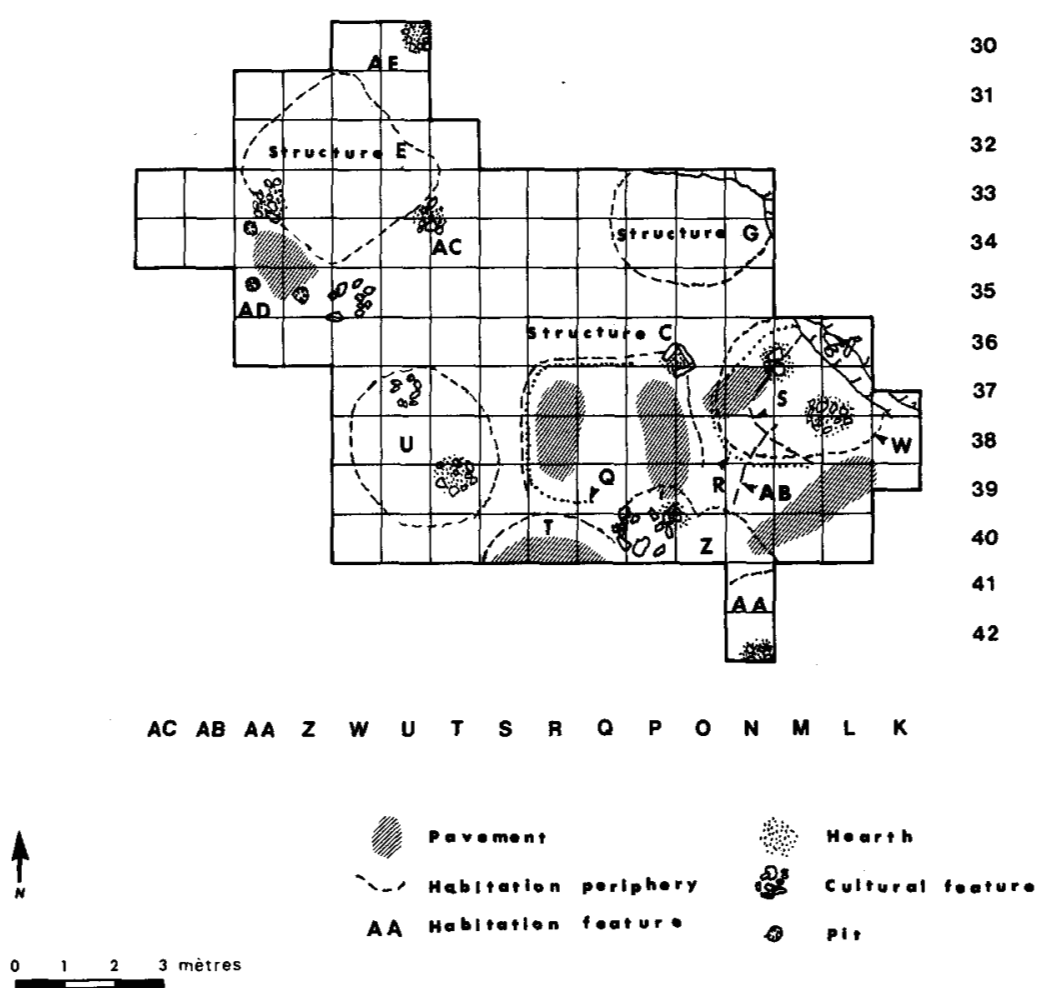

FIG. 4. Habitation features, DIA.4 (JfE1-4), 1978.

Habitation Features AC, AD, and AE are not structurally definable. These three occupations are presently identified on the basis of stratigraphic discontinuities and associated cultural features indicating activity areas; either tent dwellings or open-air encampments may be assumed. Similarly, the perimeters of the semisubterranean structures $\mathrm{Q}, \mathrm{T}, \mathrm{Z}, \mathrm{AA}$, and $\mathrm{AB}$ are either imprecisely or only partially known. This situation derives from destruction of earlier habitation peripheries by subsequent re-occupation of these dwellings, the superimposition of later habitations, and from the limited extent of the 1978 excavation area. Also, vandalization of earlier habitations by later groups for suitable construction materials such as flagstones and, possibly, sods may have affected the integrity of some of these dwellings. 
The dimensions and forms of the remaining 7 habitations are fairly clear. As indicated by Table 1 , generally small dwellings varying between 10.80 and 5.20 $\mathrm{m}^{2}$ in internal area are suggested. In terms of Harp's (1976:135) demographic calculations for Port-au-Choix and eastern Hudson Bay Dorset households, single nuclear family occupancy may be inferred for the majority of these 7 dwellings. However, as already noted, no reliable estimates are yet available for the number of individuals occupying DIA.4 at any given time.

Table 1. Dimensions of complete habitation structures excavated at DIA. 4 (JfE 1-4), 1978.

\begin{tabular}{|c|c|c|c|c|c|c|}
\hline Structure & Type of Dwelling & Form & Length (m) & Width (m) & Interior $\left(\mathbf{m}^{2}\right)$ & $\begin{array}{l}\text { Orientation of } \\
\text { Long Axis }\end{array}$ \\
\hline C & semi-subterranean & rectangular & 3.60 & 3.00 & 10.80 & E-W \\
\hline $\mathbf{E}$ & semi-subterranean & rectangular & 3.20 & 3.00 & 9.60 & NW-SE \\
\hline $\mathbf{G}$ & semi-subterranean & oval & 3.30 & 2.25 & 7.10 & WNW-ESE \\
\hline $\mathbf{R}$ & semi-subterranean & $\begin{array}{l}\text { irregular } \\
\text { square }\end{array}$ & 2.90 & 2.90 & 8.40 & NW-SE \\
\hline $\mathbf{S}$ & semi-subterranean & rectangular & 2.60 & 2.00 & 5.20 & NW-SE \\
\hline $\mathbf{U}$ & tent emplacement & oval & 3.40 & 2.90 & 7.50 & NW-SE \\
\hline $\mathbf{W}$ & tent emplacement & oval & 3.40 & 2.70 & 7.50 & NW-SE \\
\hline
\end{tabular}

\begin{tabular}{|c|c|c|c|}
\hline \multirow[b]{2}{*}{ Phase } & \multirow[b]{2}{*}{ Leve1 } & \multicolumn{2}{|c|}{ Habitation Features } \\
\hline & & Structure $c$ zone & Structure E zone \\
\hline 5 & $\begin{array}{l}\text { I } \\
\text { Ia } \\
\end{array}$ & $\begin{array}{l}\text { Habitation featur } \\
\text { suggested by spat } \\
\text { of Leve1s Is and }\end{array}$ & $\begin{array}{l}! \\
\text { res unidentified; } \\
\text { tial configuration } \\
\text { Ib }\end{array}$ \\
\hline 4 & II/IIa & $\int \mathrm{c}, \mathrm{U}$ and $\mathrm{w}$ & $\begin{array}{c}A C \text { and } A D \\
E\end{array}$ \\
\hline 3 & $\begin{array}{l}\text { II/IIb } \\
\text { III }\end{array}$ & G & \\
\hline 2 & IV & $\begin{array}{l}\mathrm{T} \\
\mathrm{Z} \\
\mathrm{R} \\
\mathrm{Q} \\
\mathrm{A} \\
\mathrm{S} \\
\end{array}$ & $\begin{array}{l}1 \\
1 \\
1 \\
1\end{array}$ \\
\hline 1 & $\mathrm{v} / \mathrm{VI}$ & $A B$ & \\
\hline & VII & Stertle b & peach deposit \\
\hline
\end{tabular}

FIG. 5. Occupation phases, DIA.4 (JfE1-4): 1978 excavation area.

\section{Occupation Phases}

The 15 identified habitation features have been stratigraphically organized into a preliminary sequence of 4 successive occupation phases (Fig. 5). In the present 
context, the term "phase" refers exclusively to use of the excavated area through time for "structured" habitation purposes. Each phase, then, is characterized by stratigraphically consistent cultural features or elements implying either habitations or domestic activity areas. Though lacking definable habitations as well as cultural features, a fifth phase is suggested by the spatial configuration of Levels Ia and Ib. While this final phase may include Level I, it should be noted that this unit yielded no evidence suggesting use of this area of the site for habitation purposes. Cultural material recovered from the sod may well post-date Occupation Phase 5 and could result from a general "nonstructured" use of this particular area.

The habitation features in each of the phases are considered as corresponding in time with the development of the delimiting stratum or strata. Although several stratigraphic truncations appear to have resulted from the re-occupation of certain structures, none of the observed habitation features are intrusive into underlying stratigraphic units. As stated earlier, neither synchroneity or duration of occupation of the constituent dwellings in the individual phases nor the length of time involved in the development of each phase is yet determinable. However, a series of 5 radiocarbon dates, presented in Table 2, indicate a period of roughly 1000 years for Phases 2 through 4 .

Table 2. Radiocarbon dates, DIA. 4 (JfE 1-4), 1978*

\begin{tabular}{|c|c|c|c|c|c|}
\hline Catalogue No. & Material & Quantity (gr.) & Level & Association & $\begin{array}{l}\text { 14C Years } \\
\text { (uncorrected) }\end{array}$ \\
\hline QC\#625 & wood charcoal & 165 & II & $\begin{array}{l}\text {-hearth, Habitation } \\
\text { Feature AD }\end{array}$ & $815 \pm 110$ (A.D. \\
\hline QC\#628 & burnt moss & 400 & IV & $\begin{array}{l}\text {-beneath the hearth } \\
\text { associated with } \\
\text { Structure S }\end{array}$ & $\begin{array}{c}1810 \pm 110 \text { (A.D. } \\
140 \text { ) }\end{array}$ \\
\hline QC\#631 & burnt moss & 135 & IV & -hearth, Structure Z & $1380 \pm 100$ (A.D. \\
\hline QC\#632 & burnt moss & 42 & IV & -hearth, Structure AA & $1660 \pm \underset{290 \text { ) }}{95}$ (A.D. \\
\hline QC\#633 & burnt moss & 200 & IV & $\begin{array}{l}\text {-upper zone of hearth } \\
\text { in Structure } S \text {; } \\
\text { presumed associated } \\
\text { with Structure R }\end{array}$ & $\begin{array}{c}1470 \pm 100 \text { (A.D. } \\
480)\end{array}$ \\
\hline
\end{tabular}

QC - Queen's College Radiocarbon Laboratory, City University of New York, Flushing, New York

Phase 1:

The earliest phase underlies the Level $\mathrm{V}$ marine deposit and is represented by Habitation Feature AB and Level VI humus (Fig. 6). This feature is interpreted as a shallow semi-subterranean dwelling of unknown dimensions. Only the northwesternmost limit of the depression forming the dwelling remains definable. A linear flagstone pavement measuring $3 \times 1$ metres occurs in the depression.

\section{Phase 2:}

The second phase is associated with Level IV humus and includes Habitation Features Q, R, S, T, Z, and AE (Fig. 7). Excluding Habitation Feature AE, all of these structures are interpreted as semi-subterranean dwellings. 


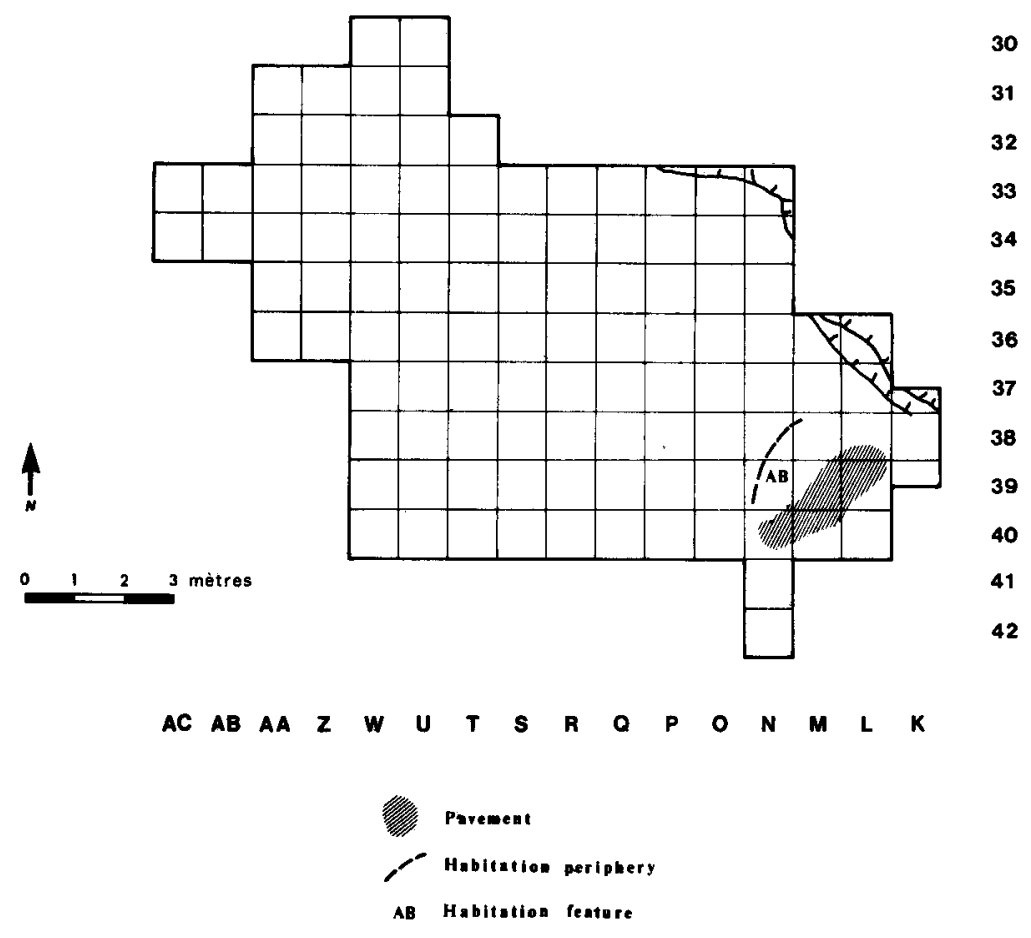

FIG. 6. DIA.4 (JfE1-4): Occupation Phase 1.

Four radiocarbon samples obtained from this phase have provided a series of dates ranging between A.D. 140 and 570. Two of these samples were obtained from a large hearth originally associated with Structure $S$ and later re-used in the superimposed Structure R. The dates from these samples (QC\#628 and \#633) allow a period of $340 \pm 110$ radiocarbon years between the construction and subsequent re-occupation of the depression forming these two dwellings.

The earliest and latest of the four determinations, both obtained on burnt moss from, respectively, Structures $S$ (QC\#628) and Z (QC\#631), may approximate the full temporal range of Phase 2 occupation. This hypothesis is based on the superimposition of cultural features and the overlapping of architectural remains of the habitation features in this phase. These observations, according with the $14 \mathrm{C}$ dates, permit the relative chronological placement of these structures. For example, the stratigraphic position of the small flagstone pavement associated with Structure $R$ indicates that this dwelling post-dates Structure $Q$. The latter dwelling, although undated, appears to follow Structure AA. Structure AA is partially overlain by Structure $Z$ which, on the basis of radiocarbon dating, is more recent than Structure R. Finally, the truncation of the western periphery of the depression representing Structure $\mathrm{Z}$ by Structure $\mathrm{T}$ indicates that the former 


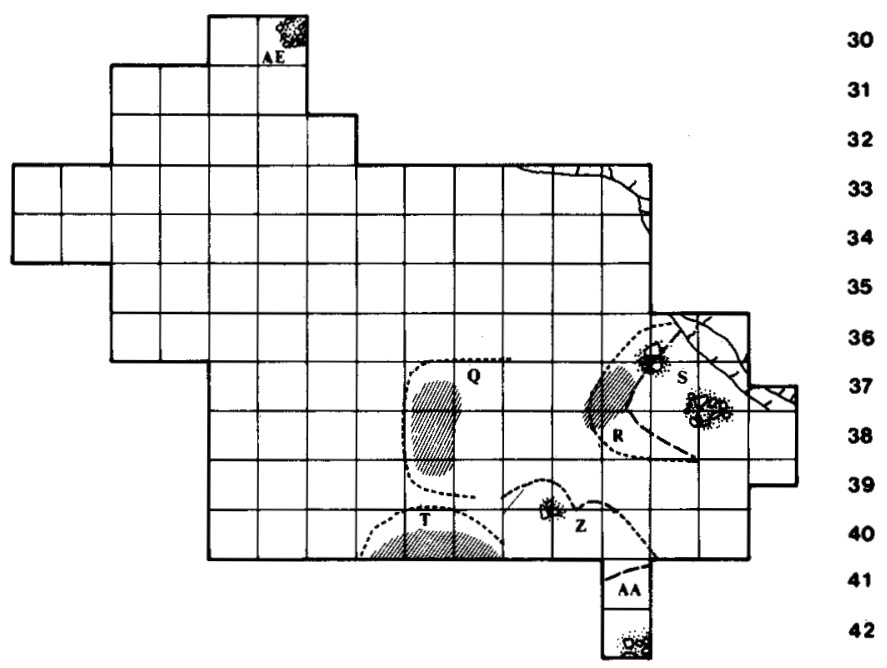

$\begin{array}{llllllllllllllll}A C & A B & A A & Z & W & U & T & S & R & 0 & P & 0 & N & M & L & K\end{array}$

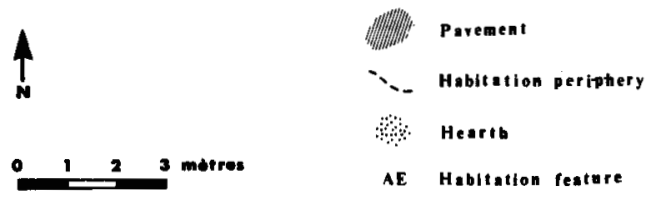

FIG. 7. DIA.4 (JfE1-4): Occupation Phase 2.

dwelling precedes the latter. Of the six semi-subterranean dwellings identified in this phase, Structure T is the most completely preserved.

\section{Phase 3:}

Phase 3 comprises Structure G, an oval semi-subterranean dwelling constructed against a bedrock outcrop (Fig. 8). This structure is associated with the deposition of Level III (obtained from the construction of the dwelling) and the humus levels II and IIb. The oblique stratigraphic situation of the IIb unit, converging with both Levels II and IV and thereby separating Level III into two 


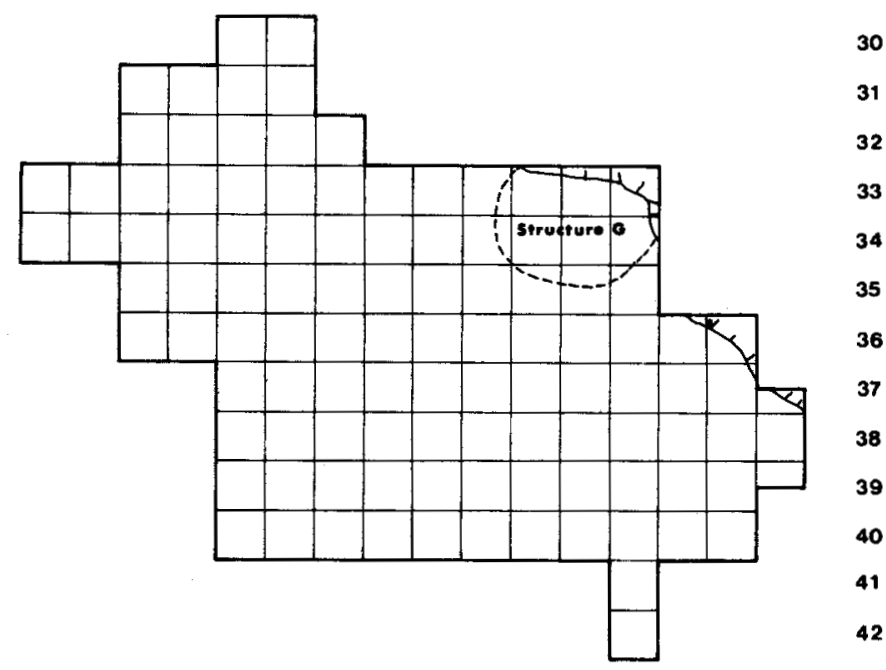

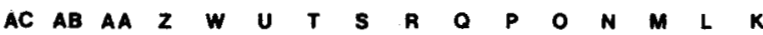

30

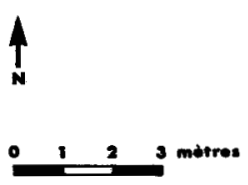

FIG. 8. DIA.4 (JfE1-4): Occupation Phase 3.

non-continuous sections, suggests that Structure G was enlarged through its western extremity either during or shortly after the initial occupation of this dwelling. However, as the data are insufficient to clearly distinguish more than one occupation, Structure $G$ is treated for the present as a single component.

\section{Phase 4:}

The fourth phase (Fig. 9) is associated with Levels II and IIa and, apparently, either rapidly follows or is partly contemporaneous with the occupation of Structure G. Architecturally, this phase is the most clearly defined and includes the semi-subterranean dwellings $\mathrm{C}$ and $\mathrm{E}$, two tent emplacements (Habitation 


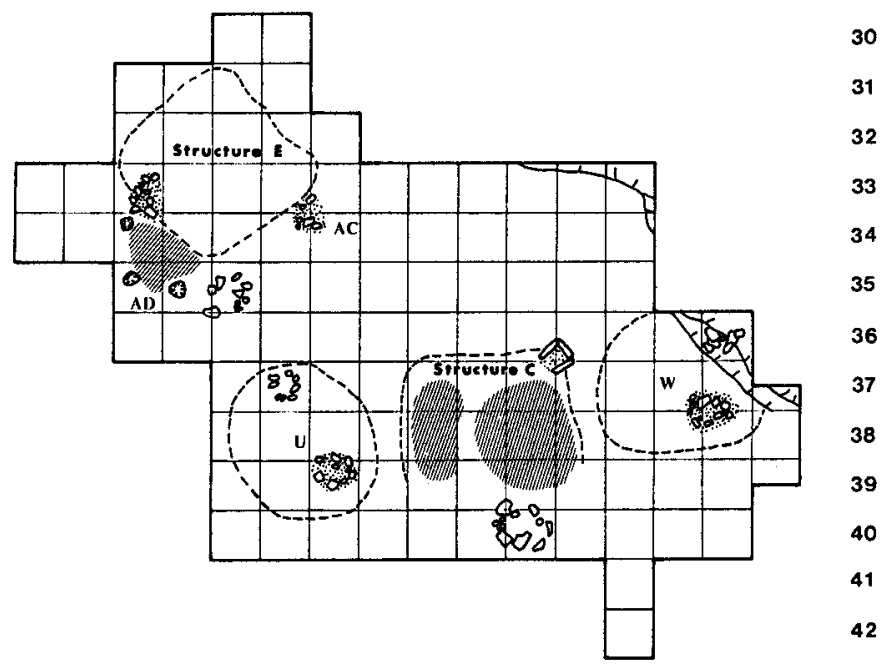

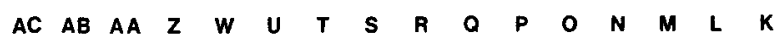

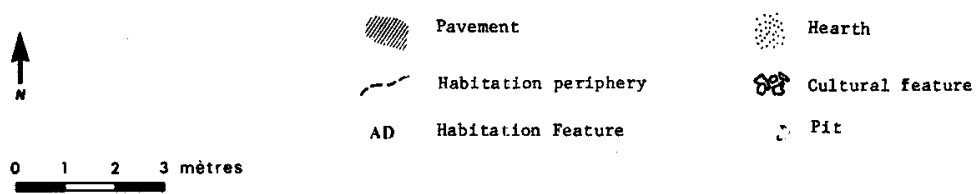

FIG. 9. DIA.4 (JfE1-4): Occupation Phase 4.

Features $\mathrm{U}$ and $\mathrm{W}$ ), and two occupation zones lacking definable structural perimeters (Habitation Features $\mathrm{AC}$ and $\mathrm{AD}$ ).

Habitation Features $A C$ and $A D$ are situated on the raised gravel rim of Structure $\mathrm{E}$ and, hence, post-date the construction of this dwelling. A single radiocarbon date obtained on wood charcoal from the hearth associated with Habitation Feature AD (QC\#625) suggests that Structure E pre-dates the mid12th century A.D. Since stratigraphic overlap with adjacent dwellings is lacking for Structure $C$ and Habitation Features $U$ and $W$, no relative chronological ordering for these dwellings is possible. Also, since the stratigraphic units in this phase are not continuous between these three structures and Structure $E$ and Habitation Features AC and AD, there is no assurance that these two groups of dwellings are contemporaneous. However, the similarity of composition of Levels II and IIa in these separate zones and the clear association of these levels with Structures $\mathrm{C}$ and $\mathrm{E}$ allows speculation on similar developmental processes for these two units. Consequently, the 4 habitations and 2 occupation zones identified in this phase are provisionally considered as relatively contemporaneous. 


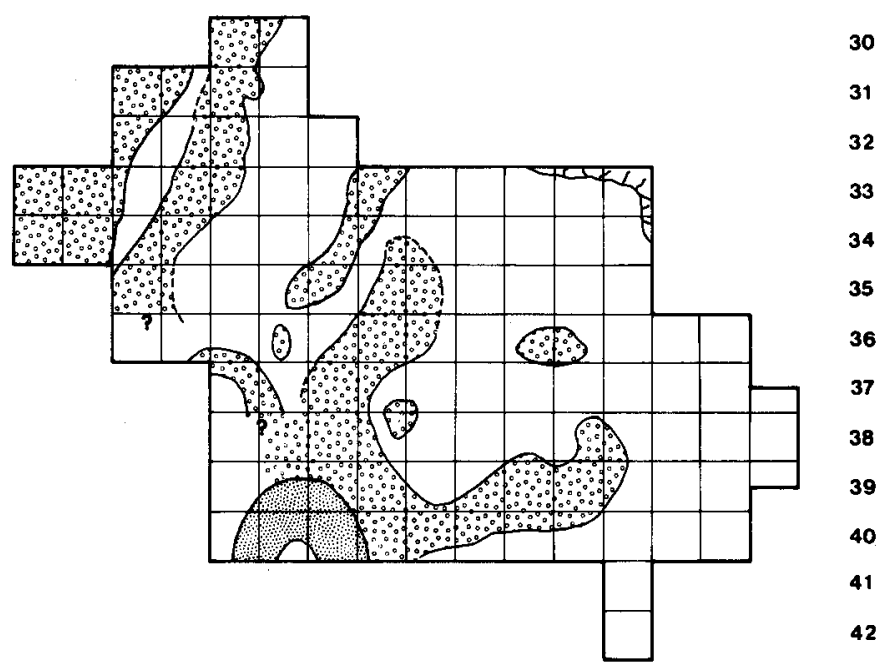

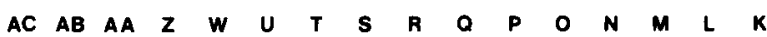

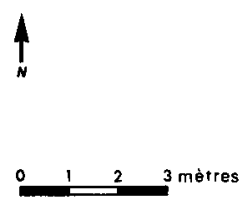

FIG. 10. DIA.4 (JfE1-4): Occupation Phase 5.

In addition, the stratigraphy recorded between the 1978 excavation area and the previously excavated Structures A and B suggests inclusion of these two dwellings as late components in this phase. This suggestion is further supported by the 14th and late 15th century A.D. radiocarbon dates for these structures.

\section{Phase 5:}

The final occupation phase (Fig. 10) consists of Levels Ia and Ib and, possibly, the sod Level I. Spatially, Level Ia corresponds closely with the perimeters of Structures $\mathrm{C}$ and $\mathrm{E}$ and thus may signify re-occupations of these house depressions. Level Ib, partly overlapping Level Ia, suggests, by its configuration, the northern extremity of an apparently oval tent emplacement. Cultural features are absent for the three units comprising this phase. 


\section{DISCUSSION}

The 1978 Tuvaaluk Programme excavation at DIA.4 produced a considerable amount of settlement-related information concerning Dorset occupation of the site. Much of this information consists of structural data indicating use through time of the excavated area for habitation purposes. The present paper represents a preliminary effort to stratigraphically organize these data into chronologically successive occupation phases within this small yet significant area of the site.

This organizational attempt is not only important to the comprehensive examination of Dorset habitation and settlement patterns but also provides a coherent framework for analysis of the cultural materials recovered from the excavation. At present, analysis of this material is proceeding according to the proposed habitation features, stratigraphic units, and occupation phases. Results of this analysis should allow clarification and refinement of the occupational pattern as well as permit inferences concerning the socio-economic systems involved in occupation of the site. As stated earlier, these results are far from complete. The following discussion, then, focuses on certain methodological implications of the excavation and includes only summary consideration of the excavation data.

Firstly, it should be noted that the bulk of the settlement information recovered was initially unanticipated; neither the complexity nor the quantity of these data was in any way suggested by pre-excavation surface indices. Thus, the recovery of these data serves to emphasize the desirability of controlled and extensive excavation of a site, including inter-structural zones and the raised peripheries of house depressions.

Secondly, the excavation of these zones at DIA.4 illustrates the potential unreliability of demographic reconstructions of sites based on surface indications. In theory as well as in practice, such reconstructions require the excavation of a considerable area within a site, the identification of (preferably) complete and incomplete habitation structures, determination of synchronic/ diachronic habitation features, and the systematic and rigorous evaluation through testing of possible occupation zones in unexcavated areas of the site. This problem is further complicated by "visibility" of patterned structural remains, the possibility of open-air encampments, and the relationships of external cultural features.

Thirdly, the approximately 1000 radiocarbon years delimiting Phases 2 through 4 suggest that consideration of altitude above sea level is of little significance to the interpretation of this particular expression of Dorset occupation. This suggestion is based on comparison of the radiocarbon dates and the isostatic rebound rates calculated for the region. The latest $14 \mathrm{C}$ date from $\mathrm{Phase}$ 2 (A.D. $570 \pm 100$ ) precedes by some 400 years the isostatically-determined formation of the $7 \mathrm{~m}$ a.s.l. beach from which this date was obtained; a maximum difference of 750 years is implied between the earliest date from this phase and uplift rates. Additionally, occupation phases more recent than Phase 2 occur at higher elevations (ca. $8.90 \mathrm{~m}$ a.s.1. for Phase 4).

These data tend to caution against the exclusive use of isostatic rates for inferring Dorset site chronology. While proximity to an active beach may have influenced the position of habitation structures in some instances, the physical 
characteristics and composition of the locality might also have figured in the selection of a site for settlement purposes. At DIA.4, prominent site characteristics include well-drained gravel beaches, linear and parallel bedrock outcrops, protection from prevailing northwesterly and northerly winds, and sheltered access to the bay. Availability of sod (though unproven) and easily recuperable construction materials (such as flagstones) from earlier habitations may be additional factors affecting the selection of the precise location of later dwellings at the site.

The above implications notwithstanding, certain observations and comments on the distribution and varieties of identified habitations are nevertheless here warranted.

Concerning spatial and elevational relationships, it is of interest to note that the Phase 2 semi-subterranean dwellings cluster in the southeastern and eastern zones of the excavated area, between 6.90 and $7.50 \mathrm{~m}$ a.s.l. The single Phase 1 habitation is also found in this zone, at a slightly lower altitude. In contrast, Phase 4 structures describe a general distribution across the excavated area and occur between 7.55 and $8.90 \mathrm{~m}$ a.s.l. A change in settlement patterning, then, may be implied between the two earliest and fourth occupation phases at the site.

The implied change appears to have been accompanied by the later use of elevationally lower beaches. A $16 \mathrm{~m}^{2}$ test at $4.50 \mathrm{~m}$ a.s.l. in 1978 revealed a shallow depression roughly $20 \mathrm{~cm}$ in depth which, on the basis of the stratigraphy and superimposed internal cultural features, is interpreted as a re-occupied dwelling structure. Acceptable radiocarbon dates of A.D. $995 \pm 90$ (QC\#629) and A.D. $1120 \pm 100$ (UQ-52*) have been obtained from two different stratigraphic units in this structure. Further samplings of this beach in 1979, comprising $72 \mathrm{~m}^{2}$, uncovered a substantial concentration of slab and blocks (containing three hearths) which is provisionally interpreted as representing a number of similar habitation features.

Use of the lower beaches, however, does not preclude the continued use of higher zones for "structured" habitation purposes. At DIA.4, truly semisubterranean dwellings occur no lower than $6.20 \mathrm{~m}$ a.s.1. As indicated by Structure A, this zone continued to be occupied by Dorset groups until the end of the 15th century A.D.

\section{REFERENCES}

CHANG, K.C. 1962. A typology of settlement and community patterns in some circumpolar societies. Arctic Anthropology 1(1):2841.

HARP, ELMER Jr. 1976. Dorset settlement patterns in Newfoundland and southeastern Hudson Bay. In: Maxwell, M. S. (ed.). Eastern Arctic Prehistory: Paleoeskimo Questions. Memoirs of the Society for American Archaeology. No. 31:119-138.

PLUMET, PATRICK. 1979. Thuléens et Dorsetiens dans l'Ungava (Nouveau-Québec). In: McCartney, Allan P. (ed.). Thule Eskimo Culture: An Anthropological Retrospective. Archaeological Survey of Canada Mercury Series No. 88:110-121.

TRIGGER, BRUCE G. 1968. The determinants of settlement patterns. In: Chang, K. C. (ed.). Settlement Archaeology. Palo Alto. CA: National Press Books. p. 53-78.

* Laboratoire de géochimie isotopique, Département des sciences de la terre de l'Université à Montréal. 